\title{
Behavioural Contagion in Hong Kong Urban Space under Mass Psychological Distress
}

\author{
Mirna Zordan, Jin Yeu Tsou \\ Department of Architecture and Civil Engineering, \\ City University of Hong Kong, Tat Chee Avenue, Kowloon, Hong Kong \\ mzordan2-c@my.cityu.edu.hk, jytsou@cityu.edu.hk \\ Tel: +85260985625
}

\begin{abstract}
Psychological factors affecting human behaviour 'a priori' are largely underestimated in the contemporary urban debate. Mass psychological distress is not considered as a factor affecting urban dynamics within city-spaces. This study compares activities, preferences, and psychological dynamics related to behavioural contagion theory towards urban spaces in Hong Kong before and after the COVID-19 outbreak. Results showed significant transitions in preferences among shopping malls and urban green spaces for stationary uses, paired with substantial changes at the destination decision-making process. Other than behavioural tendencies, these results provide directions for discussing the integration of mass psychological distress into future urban scenarios design.
\end{abstract}

Keywords: behavioural contagion, mass psychological distress, urban space, Hong Kong;

eISSN: 2398-4287@ 2020. The Authors. Published for AMER ABRA cE-Bs by e-International Publishing House, Ltd., UK. This is an open access article under the CC BYNC-ND license (http://creativecommons.org/licenses/by-nc-nd/4.0/). Peer-review under responsibility of AMER (Association of Malaysian Environment-Behaviour Researchers), ABRA (Association of Behavioural Researchers on Asians) and cE-Bs (Centre for Environment-Behaviour Studies), Faculty of Architecture, Planning \& Surveying, Universiti Teknologi MARA, Malaysia.

DOI: https://doi.org/10.21834/ebpj.v5i14.2161

\subsection{Introduction}

Human behaviour is an extremely complex mechanism driven by multiple forces. The inter-relationship between human behaviour and physical environment has been investigated over decades, trying to extrapolate basic principles behind dynamics affecting both space and human attitudes. The results achieved nowadays are remarkable. However, in the perspective of this field of investigation, less space has been dedicated to psychological factors affecting human behaviour 'a priori', and most importantly all the theories explored are based on behavioural attitudes driven by standard psychological conditions. Hence, the relationship between environment and behaviour can be dramatically questioned and re-discussed if an unexpected distortion of mass psychological condition occurs. The spread of a pandemic can induce this distortion. More specifically, during a pandemic outbreak, another typology of contagion rather than physical is under observation. The spread of the disease in some cases impacts the most psychological conditions and perceptions of the affected population rather than the effective dissemination of the disease itself (Dodds \& Watts, 2004; Epstein, Parker, Cummings, \& Hammond, 2008; Huremovic, 2019), endorsing and questioning the power of behavioural contagion in impacting on human attitudes, and consequently on urban dynamics and public life. However, no attention has been given to the effects that a pandemic, and especially behavioural contagion, can arise in high-density environments towards the use of the public realm within the cities' space as yet.

The provision and management of public spaces are increasingly becoming problematic and difficult to operationalise (Carmona, 2010), especially in high-density environments. However, the complexity and multidimensionality of public spaces advocate them as essential elements within city spaces, above all, where scarcity of available space is a contemporary issue. The impact of public spaces on wellbeing and quality of life is internationally recognised as affecting mental, physical, and social conditions of urban dwellers by an enormous quantity of studies (Bishop \& Marshall, 2017; Francis, Giles-Corti, Wood, \& Knuiman, 2012; Hanan, 2017; Nasution \& Zahrah,

eISSN: 2398-4287C 2020. The Authors. Published for AMER ABRA cE-Bs by e-International Publishing House, Ltd., UK. This is an open access article under the CC BYNC-ND license (http://creativecommons.org/licenses/by-nc-nd/4.0/). Peer-review under responsibility of AMER (Association of Malaysian Environment-Behaviour Researchers), ABRA (Association of Behavioural Researchers on Asians) and cE-Bs (Centre for Environment-Behaviour Studies), Faculty of Architecture, Planning \& Surveying, Universiti Teknologi MARA, Malaysia.

DOI: https://doi.org/10.21834/ebpj.v5i14.2161 
2018; UN-Habitat, 2013; Villanueva et al., 2015, among others). Thus, it is fundamental to investigate behavioural patterns towards different public spaces typologies and to understand the urban population perceptions and preferences among them to develop better redistribution and development strategies (Zordan, 2018). If these patterns have been widely explored under conventional or standard psychological conditions, there is no study that considers mass psychological distress as a driving force affecting behavioural patterns towards the public realm.

\subsection{Aim of the study}

This research aims at exploring the impact of mass psychological distress on different uses of urban spaces in Hong Kong, and decisionmaking processes behind them. The investigation of preferences and decision-making dynamics before and after the spread of Covid19 will allow the initial detection of transitional processes and behavioural dynamics in Hong Kong urban population, emphasising the current need of attention of mass psychological distress in urban environment studies.

\subsection{Objective of the study}

This study has two objectives. Firstly, it will detect transitions in preferences and activities among different typologies of urban spaces before and after the spread of Covid-19 trying to extrapolate initial tendencies on which spaces are more resilient than others. This, to get an initial portrait of behavioural dynamics leading urban dwellers to choose some urban spaces rather than others. Secondly, the study will focus on the decision-making processes lying behind those preferences by investigating psychological attitudes deriving from behavioural contagion theory principles. These psychological and behavioural dynamics towards the urban environment will point out population needs, allow primordial evaluation tools about current urban spaces (concerning population needs fulfilment), and suggest directions for the design of future urban spaces.

\subsection{Literature review}

Psychological dynamics are at the basis of every action, and the relationship between those factors, human behaviour and physical environment are synthesised in Fig.1. In the case of extreme distress affecting an entire population, if not the world as a whole, those mass psychological factors decisively determine consequences on human behaviours and attitudes.

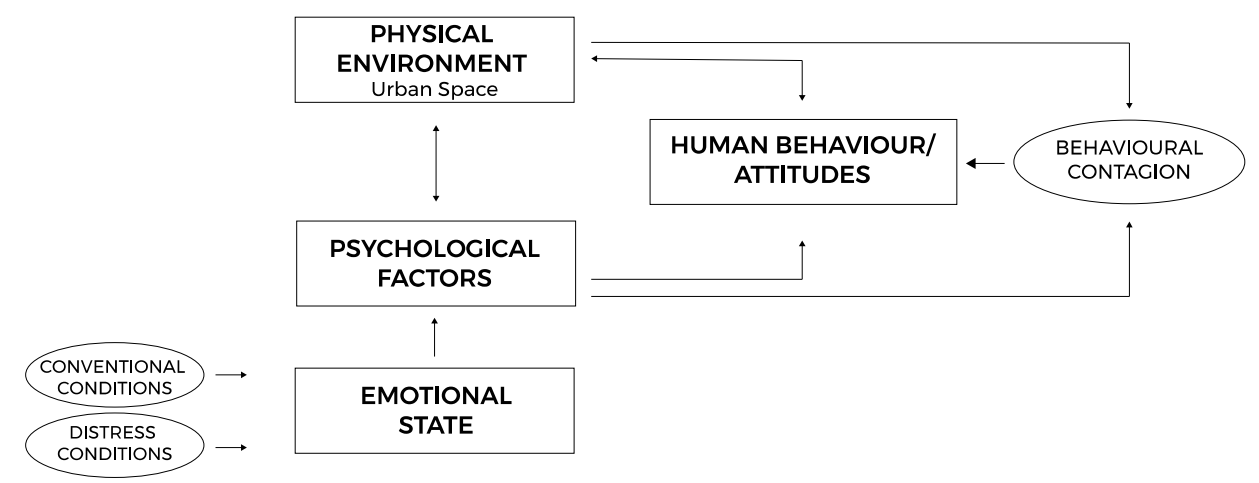

Fig. 1: Conceptual framework of the study. (source: Mirna Zordan)

In the case of a pandemic, contagion occurs not only related to the physical transmission of the disease. Psychological perceptions, such as fear and perceived risks, in some cases are spreading faster than the disease itself (Epstein et al., 2008; Rubin, Amlôt, Page, $\&$ Wessely, 2009). Thus, the consequences on human perceptions are undeniably impacting on behavioural dynamics. In this scenario, the word 'contagion' appears to be the most appropriate to define dynamics related to both physical and psychological transmission of states. Contagion theory refers to collective behaviours that investigates how the crowd, or mass, can affect individuals behaviours (Huremovic, 2019; Le Bon, 1896), and its psychology can be primarily divided into emotional and behavioural contagion (Hatfield, Cacioppo, \& Rapson, 1992; Huremovic, 2019; Wheeler, 1966). Hence, when investigating human behaviour in relation to the built environment, the phenomenon of behavioural contagion draws attention into the field. Defined firstly in 1950 as an event in which a recipient's behaviour has changed to become "more like" that of the actor or initiator. This change has occurred in a social interaction in which the actor has not communicated intent to evoke such a change (Polansky, Lippitt, \& Redl, 1950, p.322), behavioural contagion definition did not distinguish from other types of social influence. To keep the definition still open, Wheeler (1966), applied a reduction of sentences (Carnap, 1936, 1937; Wheeler, 1966) to keep using the word 'behavioural contagion'. The Encyclopedia of Social Psychology defines it more synthetically as the tendency of people to repeat behaviour after others have performed it (van Baaren, 2007). For behavioural contagion to occur, there is a need of face to face interaction; it usually occurs subconsciously, and it requires at least one imitator and one initiator. The principles on which behavioural contagion is based are: acute conflict in the area within the imitator; high-degree liability of personal balance; strong urge towards impulse expression along the same line of initiator; impulse satisfaction of initiator without fear of guilt (Redl, 1949; Wheeler, 1966). Despite the enormous amount of studies that applied the concept 
of behavioural contagion into different fields mostly related to medical sciences (Suzuki, Jensen, Bossaerts, \& O'Doherty, 2016), sociology and psychology (Shirado, Crawford, \& Christakis, 2020), transportation research (Allen, Muñoz, \& Ortúzar, 2019), to mention few, there is no application of this theory in urban studies specifically looking at the influence of behavioural contagion on decisionmaking processes related to the use of urban spaces under mass psychological distress (Bish \& Michie, 2010; Jones \& Salathé, 2009; Rubin et al., 2009).

\subsection{Methodology}

This pilot study follows an exploratory research methodology. The project is divided into two main stages following the research objectives; the first with the purpose of detecting behavioural patterns transitions, the second focusing on the investigation of the decision-making processes behind them. The categorisation of public spaces was made based on accessibility and intersubjectivity criteria, excluding the intertwine between public and private (Carmona, 2010; Kohn, 2004); management, ownership, and land value are not considered in this preliminary stage. Due to the nature of the research, survey research design and in-depth interviews were selected as principal methods of investigation. The target of the pilot study analysed in this paper was set to Hong Kong young generations, specifically university students, due to data availability and sample collecting issues given by the current Covid-19 situation that did not allow on-site research-related activities.

\subsection{Data collection}

Due to exploratory research principles, this study does not aim at inferential analysis; therefore non-probability sampling was adopted (Saunders, Lewis, \& Thornhill, 2009), by applying a self-selection sampling technique (Saunders et al., 2009). The study's need of cases was advertised among university students by emails and invitations from colleagues and friends, data were collected only from respondents (Saunders et al., 2009) between $6^{\text {th }}$ and $19^{\text {th }}$ of April 2019.

\subsection{Data analysis procedure}

Data analysis was also carried out in two stages. The first was dedicated to the survey data and the detection of patterns with a preference analysis. The second part mostly involved in-depth interviews focused on decision-making processes and questions related to behavioural contagion dynamics.

\subsection{Preference analysis}

The survey was designed into two sections, one before the spread of the COVID-19 and one at the present time. Questions were related to the use of the public realm in Hong Kong and preferences of urban spaces typologies for stationary (social/optional) activities (Gehl, 1987; Ghel \& Svarre, 2013; Mehta \& Bosson, 2018; W. H. White, 1980). The measurement considered more appropriate was set on Likert-type items (Boone \& Boone, 2012) in most questions. Based on this decision, data analysis was based on the school of thoughts that treats Likert-type items as ordinal variables (Boone \& Boone, 2012), significance was tested with Chi-square test.

\subsection{Behavioural Analysis}

In-depth interviews were conducted based on a voluntary bias after compiling the survey. The principles related to behavioural contagion theory were preliminarily tested by asking specific questions related to choices and psychological dynamics. Important parameters to be detected were hesitation in decision-making and decisiveness in self-initiative behaviour.

\subsection{Findings}

\subsection{Demographics}

Survey respondents $(n=113)$ were male $(44 \%)$ and female $(56 \%)$ university students, aged mostly between $15-24(57 \%)$, and $25-34$ $(41 \%)$, with a minor percentage, ranged in $35-44$ years old $(3 \%)$. As the target was set on university students, level of education only comprehends junior college or undergraduate (46\%), and postgraduate and above (54\%). The majority of respondent were from Hong Kong (48\%), and Mainland China (33\%), with smaller percentages from South East Asia (6\%), Africa (6\%), Europe (3\%), Central Asia $(1 \%)$, US (1\%), and Russia (1\%).

\subsection{Activities and frequencies}

A visual portrait of activities and frequencies is immediately highlighting the dropping of high and medium frequencies of social and optional activities, and the enhancement of low frequencies spreading around both necessary and social or optional activities, see Fig.2 and Fig.3. Percentages are shown in Table 1. The highest decrease of frequency reached the null value in hanging out with friends (from $7 \%$ to $0 \%$ ), and sport (from $6.31 \%$ to $0 \%$ ). The highest percentages reached (over $40 \%$ ) are related mostly to low frequencies. Before the spread of Covid-19, low frequencies are mostly concerning the use of public services (44.5\%), and going out without plans $(45.5 \%)$, while after the spread of Covid-19 percentages relate to going out $(75.22 \%)$, going out for lunch or dinner $(43.75 \%)$, going out 
for shopping (46.43\%), use of public services (45.54\% for rarely, $40.18 \%$ for never), hanging out with family $(62.50 \%)$, sport (46.43\%), getting fresh air $(40.18 \%)$, and going out with no plans $(50 \%)$.

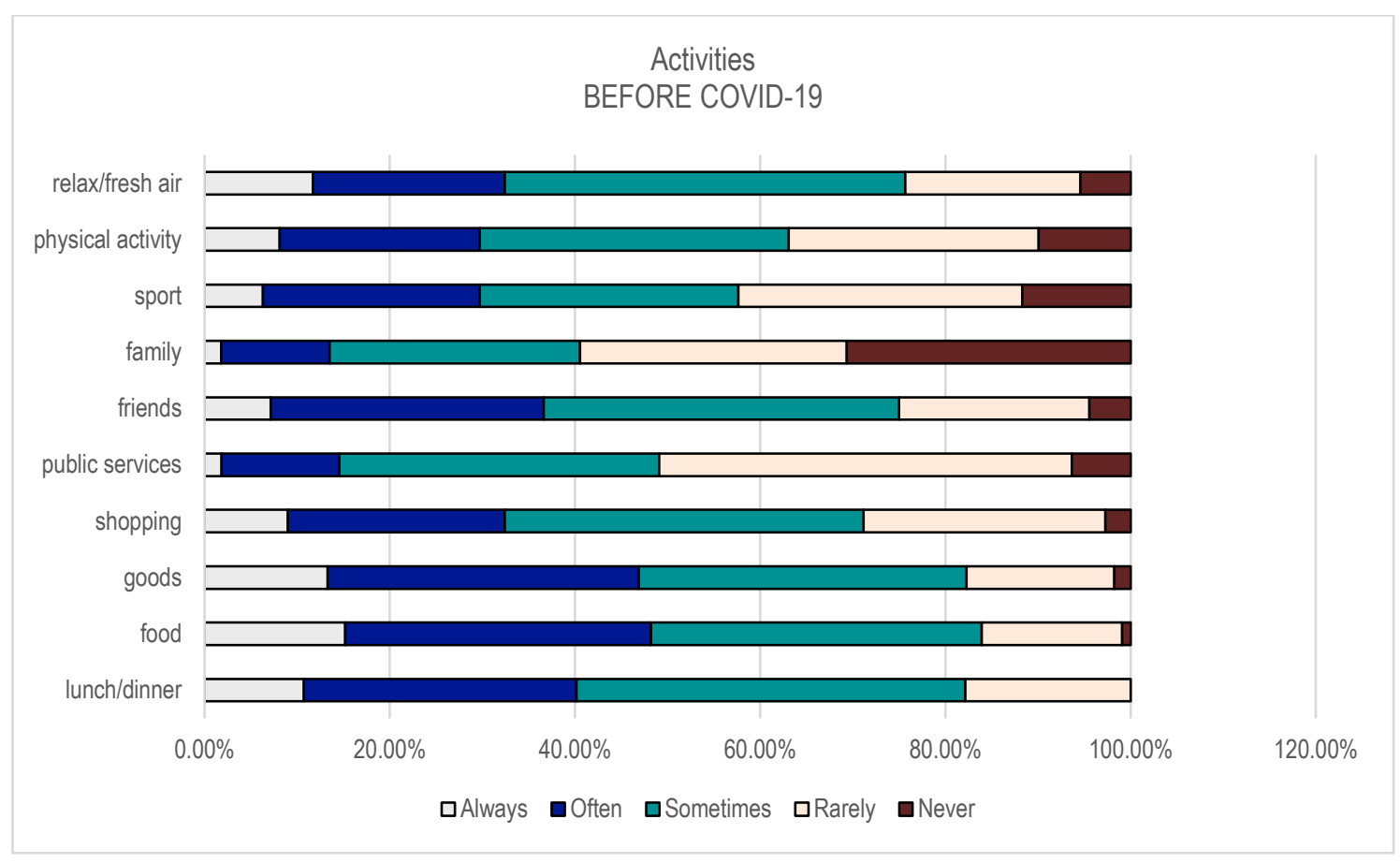

Fig. 2: Activities before the spread of Covid-19. (source: Mirna Zordan)

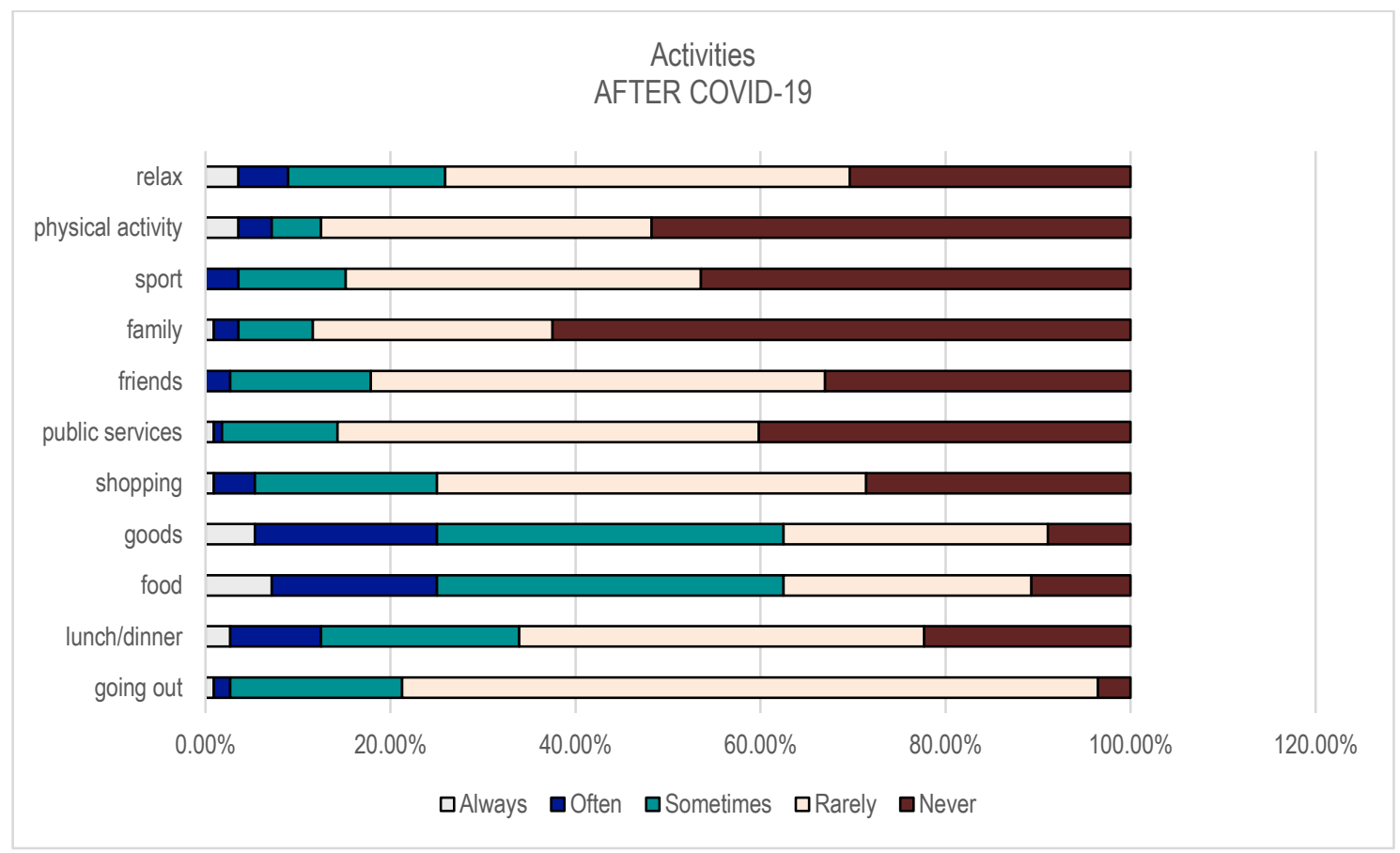

Fig. 3: Activities after the spread of Covid-19.

(source: Mirna Zordan) 
Table 1. Percentages of frequencies and activities before(b) and after(a) Covid-19 outbreak.

\begin{tabular}{|c|c|c|c|c|c|c|c|c|c|}
\hline \multirow[t]{2}{*}{ Activities } & \multirow[t]{2}{*}{ Question } & \multirow{2}{*}{$\begin{array}{r}\text { Before(b)/ } \\
\text { After(a) }\end{array}$} & \multirow{2}{*}{$\begin{array}{l}\text { Total } \\
\text { (n) }\end{array}$} & \multirow{2}{*}{$\begin{array}{c}\text { MEDIAN- } \\
\text { MODE }\end{array}$} & \multicolumn{5}{|c|}{$\begin{array}{l}\text { Likert-type } \\
\text { (percentages) }\end{array}$} \\
\hline & & & & & Always & Often & Sometimes & Rarely & Never \\
\hline \multirow[t]{2}{*}{ Frequency } & \multirow[t]{2}{*}{ How often do you go out } & $b$ & 113 & $4-4$ & $7,08 \%$ & $48,67 \%$ & $38,05 \%$ & $6,19 \%$ & $0,00 \%$ \\
\hline & & a & 113 & $2-2$ & $0,88 \%$ & $1,77 \%$ & $18,58 \%$ & $75,22 \%$ & $3,54 \%$ \\
\hline \multirow{8}{*}{ Necessary } & \multirow[t]{2}{*}{$\begin{array}{l}\text { How often do you go out for } \\
\text { lunch/dinner }\end{array}$} & $b$ & 112 & $3-3$ & $10,71 \%$ & $29,46 \%$ & $41,96 \%$ & $17,86 \%$ & $0,00 \%$ \\
\hline & & a & 112 & $3-3$ & $2,68 \%$ & $9,82 \%$ & $21,43 \%$ & $43,75 \%$ & $22,32 \%$ \\
\hline & \multirow[t]{2}{*}{$\begin{array}{l}\text { How often do you go out for } \\
\text { buying food }\end{array}$} & $b$ & 112 & $3-3$ & $15,18 \%$ & $33,04 \%$ & $35,71 \%$ & $15,18 \%$ & $0,89 \%$ \\
\hline & & a & 112 & $3-3$ & $7,14 \%$ & $17,86 \%$ & $37,50 \%$ & $26,79 \%$ & $10,71 \%$ \\
\hline & \multirow[t]{2}{*}{$\begin{array}{l}\text { How often do you go out for } \\
\text { buying goods }\end{array}$} & $b$ & 113 & $3-3$ & $13,27 \%$ & $33,63 \%$ & $35,40 \%$ & $15,93 \%$ & $1,77 \%$ \\
\hline & & a & 112 & $2-2$ & $5,36 \%$ & $19,64 \%$ & $37,50 \%$ & $28,57 \%$ & $8,93 \%$ \\
\hline & \multirow{2}{*}{$\begin{array}{l}\text { How often do you go out for } \\
\text { public services } \\
\text { (bank, doctor, etc.) }\end{array}$} & $b$ & 110 & $3-3$ & $1,82 \%$ & $12,73 \%$ & $34,55 \%$ & $44,55 \%$ & $6,36 \%$ \\
\hline & & a & 112 & $2-2$ & $0,89 \%$ & $0,89 \%$ & $12,50 \%$ & $45,54 \%$ & $40,18 \%$ \\
\hline \multirow{15}{*}{ Social/Optional } & \multirow[t]{2}{*}{$\begin{array}{l}\text { How often do you go out for } \\
\text { shopping }\end{array}$} & $b$ & 111 & $2-2$ & $9,01 \%$ & $23,42 \%$ & $38,74 \%$ & $26,13 \%$ & $2,70 \%$ \\
\hline & & a & 112 & $2-2$ & $0,89 \%$ & $4,46 \%$ & $19,64 \%$ & $46,43 \%$ & $28,57 \%$ \\
\hline & \multirow{2}{*}{$\begin{array}{l}\text { How often do you go out for } \\
\text { hanging out with friends }\end{array}$} & $b$ & 112 & $3-3$ & $7,14 \%$ & $29,46 \%$ & $38,39 \%$ & $20,54 \%$ & $4,46 \%$ \\
\hline & & $a$ & 112 & $1-1$ & $0,00 \%$ & $2,68 \%$ & $15,18 \%$ & $49,11 \%$ & $33,04 \%$ \\
\hline & \multirow{2}{*}{$\begin{array}{l}\text { How often do you go out for } \\
\text { hanging out with family }\end{array}$} & $b$ & 111 & $2-1$ & $1,80 \%$ & $11,71 \%$ & $27,03 \%$ & $28,83 \%$ & $30,63 \%$ \\
\hline & & a & 112 & $2-1$ & $0,89 \%$ & $2,68 \%$ & $8,04 \%$ & $25,89 \%$ & $62,50 \%$ \\
\hline & \multirow{2}{*}{$\begin{array}{l}\text { How often do you go out for } \\
\text { sport }\end{array}$} & $b$ & 111 & $3-2$ & $6,31 \%$ & $23,42 \%$ & $27,93 \%$ & $30,63 \%$ & $11,71 \%$ \\
\hline & & $a$ & 112 & $1-1$ & $0,00 \%$ & $3,57 \%$ & $11,61 \%$ & $38,39 \%$ & $46,43 \%$ \\
\hline & \multirow{2}{*}{$\begin{array}{l}\text { How often do you go out for } \\
\text { physical activity }\end{array}$} & $b$ & 111 & $3-3$ & $8,11 \%$ & $21,62 \%$ & $33,33 \%$ & $27,03 \%$ & $9,91 \%$ \\
\hline & & a & 112 & $2-2$ & $3,57 \%$ & $3,57 \%$ & $5,36 \%$ & $35,71 \%$ & $51,79 \%$ \\
\hline & \multirow{3}{*}{$\begin{array}{l}\text { How often do you go out to } \\
\text { relax/fresh air } \\
\text { How often do you go out to } \\
\text { relax } \\
\text { How often do you go out for } \\
\text { fresh air }\end{array}$} & $b$ & 111 & 3-3 & $11,71 \%$ & $20,72 \%$ & $43,24 \%$ & $18,92 \%$ & $5,41 \%$ \\
\hline & & $a$ & 112 & $2-2$ & $3,57 \%$ & $5,36 \%$ & $16,96 \%$ & $43,75 \%$ & $30,36 \%$ \\
\hline & & $a$ & 112 & $1.5-1$ & $2,68 \%$ & $10,71 \%$ & $19,64 \%$ & $40,18 \%$ & $26,79 \%$ \\
\hline & \multirow{2}{*}{$\begin{array}{l}\text { How often do you go out with } \\
\text { no plans }\end{array}$} & $b$ & 111 & $2-2$ & $2,70 \%$ & $17,12 \%$ & $27,93 \%$ & $45,05 \%$ & $7,21 \%$ \\
\hline & & $a$ & 112 & $2-2$ & $0,89 \%$ & $3,57 \%$ & $15,18 \%$ & $30,36 \%$ & $50,00 \%$ \\
\hline
\end{tabular}

\subsection{Preference among urban spaces}

Survey respondents were asked to choose only one space among six typologies in which they were hanging out the most before the spread of Covid-19 and in which they are/would like to hang out now. Based on this question about decision making and preference of space, the null hypothesis $\left(\mathrm{H}_{0}\right)$ and the alternative hypothesis $\left(\mathrm{H}_{1}\right)$ previously set were as follow:

$\mathrm{H}_{0}=$ there is no preference in choosing some typologies of urban spaces among others;

$\mathrm{H}_{1}=$ there is a preference in choosing some typologies of urban spaces among others;

Likert-type items were tested performing Chi-square test. Results were positive and allowed the rejection of the null hypothesis at a 0.1 significance level $(p=70,8$, d.f. $=5)$. Survey respondents' preferences towards the use of urban spaces to hang out were mostly referred to shopping malls $(44 \%)$, followed by urban green spaces $(19 \%)$, public sports facilities $(18 \%)$, urban streets $(15 \%)$, street markets $(3 \%)$, and outdoor dining areas (2\%) before the spread of the Covid-19, see Fig. 4. After the spread results significantly changed reverting the podium: urban green spaces $(65 \%)$, and malls $(17 \%)$. Other categories consistently dropped in preference, public sports facilities ( $9 \%)$, urban streets $(7 \%)$, street markets $(1 \%)$, and outdoor dining areas reaching $0 \%$, see Fig. 5 . Of all participants, $63 \%(n=69)$, 
switched preference. In-depth interviews revealed that preferences related to shopping malls involved climate factors (summer too hot), and convenience ("I can find everything I need there"), paired with the cleanliness of space. On the other hand, the switch to urban green spaces highlighted the need for lower levels of density and natural ventilation, nonetheless the urge of physical activity and selfhealing processes related to the presence of green.

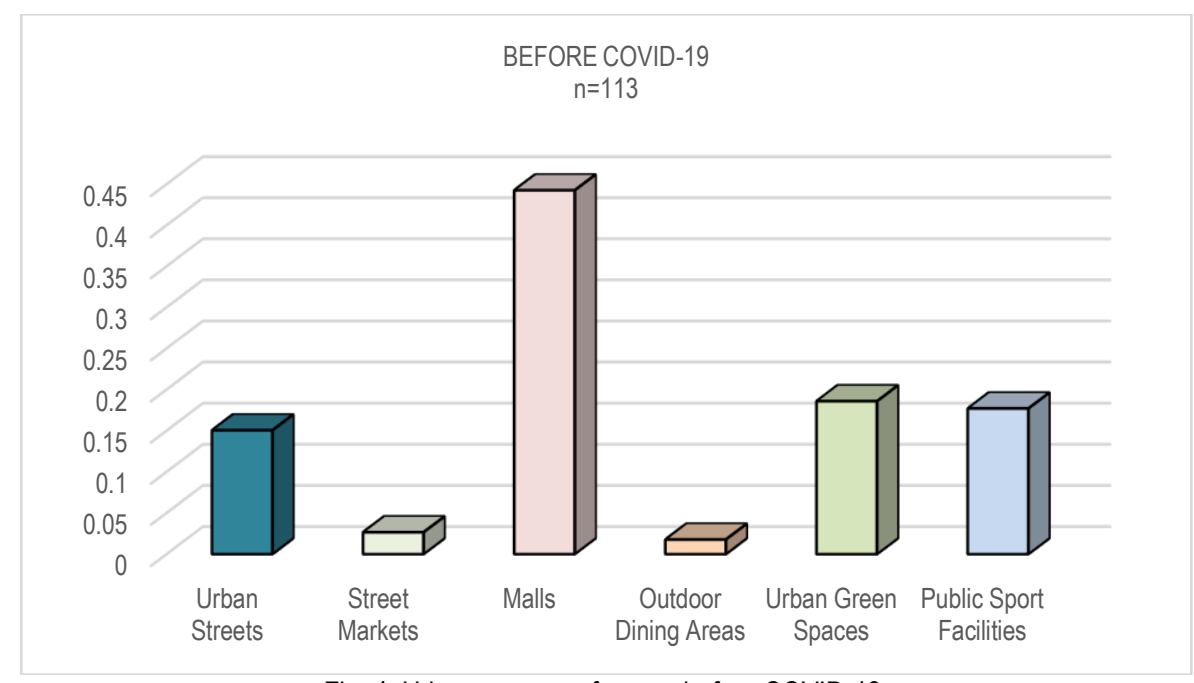

Fig. 4. Urban space preference before COVID-19. (source: Mirna Zordan)

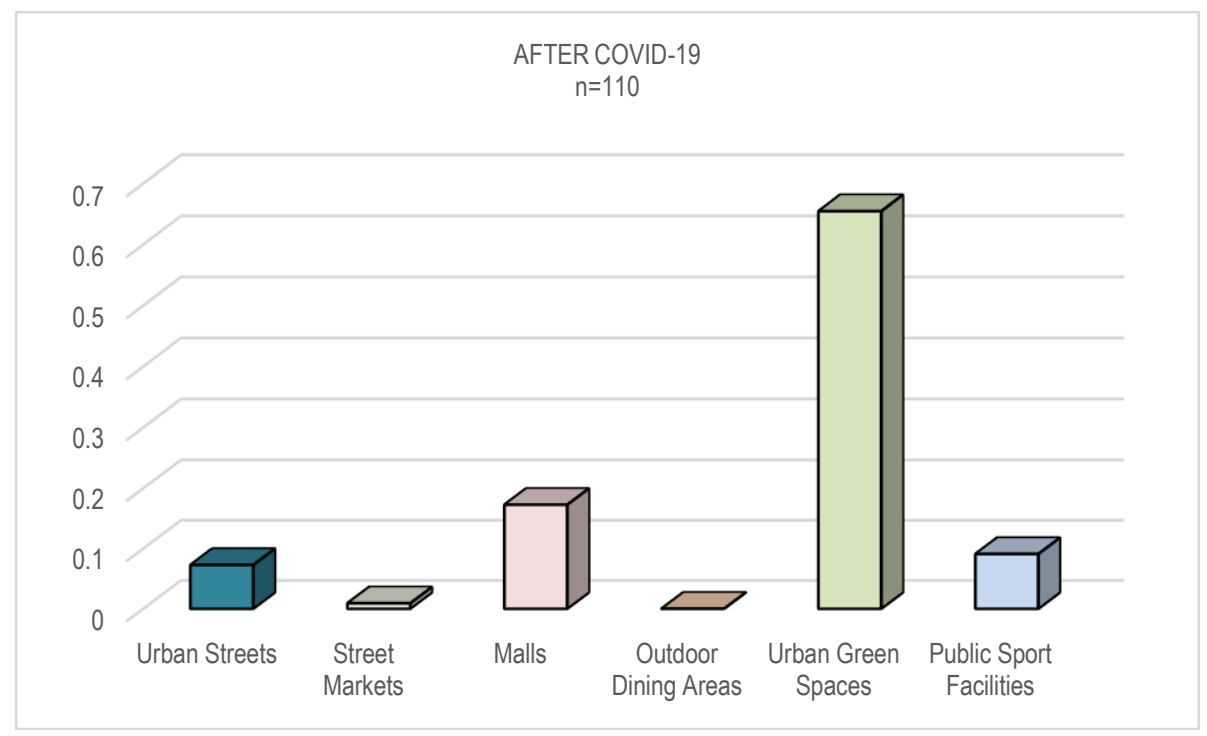

Fig. 5. Urban space preference after COVID-19. (source: Mirna Zordan)

\subsection{Behavioural contagion}

In-depth interviews were conducted among volunteers to verify the eventual presence of behavioural contagion theory principles and to explore psychological dynamics affecting the decision-making process. The majority of interviewees (71\%), was adopting self-initiative behaviour (initiator) before Covid-19 and switched to imitative behaviour (imitator) after the spread. Reversely, participants who were following other people's choices before Covid-19 reverted their attitude by self-deciding their destination; however, those participants represented a minority (29\%). All the interviewees showed no hesitation and no sign of fear or guilt in replying questions related to selfinitiative behaviour such as "If you decide to go, are you debated about going there?". When imitative behaviour tends to appear, in the question "If you go there because you want to, are the others following you without hesitation?", hesitation resulted more evident, even if the final call consisted of going to the designated place. Moreover, when talking about imitative behaviour, participants tended to show willingness and urge towards activities but not towards the final destination: "I don't care too much if we are going there, I just follow them". Most of them followed initiators mostly for scope and not for place. In a few cases, even if finally going, they would rather go to 
another place: "I would rather go somewhere else". Most generally, none of the interviewees kept the same attitude before and after the Covid-19 outbreak and, as expected, levels of hesitation increased after the spread of Covid-19.

\subsection{Discussion}

\subsection{Preference of spaces and activities}

The overall trend decreased high frequency of activities and increased low frequencies. Necessary activities drastically dropped but still survived, while social and optional activities experienced a more dramatic drop, bringing to a null value the possibly two most important activities for young generations: hanging out with friends and sports. Previous space preferences allowed the coexistence of social, optional and necessary activities, while the major shift in preferences of spaces now reveals a more evident separation between the two categories. The switch from malls towards urban green spaces indicates an expected preference of outdoor spaces, prioritising natural ventilation and natural sunlight, lower levels of density, and the need of self-healing processes related to the presence of green. This major overturn in priorities reveals the intrinsic importance of elements outdoor-related if compared to indoor-related ones. Nonetheless, the prevalence of outdoor spaces preferences despite adverse climate conditions. The separation of activities, and the preference, as expected, towards outdoor and environmental factors can have a strong repercussion in a high-density environment such as Hong Kong, where the scarcity of available land and its non-versatility represent an actual concern.

\subsection{Decision-making and behavioural contagion}

The testing of behavioural contagion presence in participants revealed positive results. Assuming the second principle (Wheeler, 1966) as already present due to mass distress conditions, the other principles seemed to be most likely satisfied after the spread. The prevalence of imitative behaviours after COVID-19 points out the weakening of self-initiative responses to urban preferences, highlighting the leaning back of optional and social activities related to groups. Besides the necessity of becoming versatile, implications towards the actual urban environment concern future needs of urban spaces capable of hosting more group-related activities. The underlining integration of mass psychological distress, and consequently of psychological factors affecting the urban population, into the design of future urban scenarios appear as inevitable.

\subsection{Limitations of the study}

Limitations related to the methodology concern sample size and targeted population for this pilot study. Data showed in this study represent initial portraits of tendency, but do not allow accuracy of statements nor inferential analysis. Future directions should consider the implementation of the sample size and the widening of the population target to include other social groups. Moreover, the research should become a longitudinal study to better capture variations and transition of human behaviour towards the use of urban space. Another limitation of the study relies on the categorisation of urban spaces, as some categories were left out.

\subsection{Conclusion and Recommendations}

The impact of psychological mass distress on behavioural choices and preferences towards the use of urban spaces is a factor in need of more attention and exploration for future urban scenarios. Results of this study revealed that actual transitions in preference of urban spaces and activities, nonetheless in behavioural dynamics and related decision-making processes, significantly occur under a mass psychological distress condition. Results provided initial evidence about factors prioritised by young generations concerning the urban environment and dynamics of decision-making processes. This study advocates attention and more consideration of population needs in case of emergencies, aiming at redefining cities spaces capable of adaptation and survival. The relevance of urban green spaces emerges here as a 'need for attention' factor influencing urban dwellers relief and wellbeing. Nonetheless, environmental factors here are prevailing above convenience and consumer-oriented solutions, questioning the actual Hong Kong model. However, despite the expected results, solutions to provide more versatile and flexible spaces have to be explored under the light of initial tendencies revealed in this study. Moreover, future challenges and research will include an in-depth exploration of mass psychological distress, behavioural dynamics and their relationship with the urban environment, aiming at bridging the fields with correlational elements.

\section{Acknowledgements}

We would like to thank all volunteers and survey participants, nonetheless all colleagues and people that helped with the spread of the survey.

\section{References}

Allen, J., Muñoz, J. C., \& Ortúzar, J. de D. (2019). On evasion behaviour in public transport: Dissatisfaction or contagion? Transportation Research Part A: Policy and Practice, 130(August), 626-651. 
Bish, A., \& Michie, S. (2010). Demographic and attitudinal determinants of protective behaviours during a pandemic: A review. British Journal of Health Psychology, 15(4), 797-824.

Bishop, K., \& Marshall, N. (2017). Social Interactions and the Quality of Urban Public Space. Encyclopedia of Sustainable Technologies (Vol. 2). Elsevier.

Boone, H. N. J., \& Boone, D. A. (2012). Analyzing Likert Data. Journal of Extension, 50(2), 207-209.

Carmona, M. (2010). Contemporary public space, part two: Classification. Journal of Urban Design, 15(2), 157-173.

Carnap, R. (1936). Testability and Meaning. Philosophy of Science, 3(4), 419-471.

Carnap, R. (1937). Testability and Meaning_Continued. Philosophy of Science, 4(1), 1-40.

Dodds, P. S., \& Watts, D. J. (2004). Universal behavior in a generalized model of contagion. Physical Review Letters, 92(21), 1-4.

Epstein, J. M., Parker, J., Cummings, D., \& Hammond, R. A. (2008). Coupled contagion dynamics of fear and disease: Mathematical and computational explorations. PLOS ONE, 3(12).

Francis, J., Giles-Corti, B., Wood, L., \& Knuiman, M. (2012). Creating sense of community: The role of public space. Journal of Environmental Psychology, 32(4), 401409.

Gehl, J. (1987). Life Between Buildings (6th ed.). Copenaghen: The Danish Architectural Press.

Ghel, J., \& Svarre, B. (2013). How to Study Public Life. Washington: Island Press.

Hanan, H. (2017). Every Day Practices and Experiential Urban Space. Asian Journal of Environment-Behaviour Studies, 2(5), 27.

Hatfield, E., Cacioppo, J. T., \& Rapson, R. L. (1992). Primitive emotional contagion. Emotion and Social Behavior, (August), 151-177.

Huremovic, D. (2019). Psychiatry of Pandemics. A Mental Health Response to Infection Outbreak. Springer.

Jones, J. H., \& Salathé, M. (2009). Early assessment of anxiety and behavioral response to novel swine-origin influenza a(H1N1). PLoS ONE, 4(12), 2-9.

Kohn, M. (2004). Brave new neighborhoods. The privatization of public space. New York and London: Routledge.

Le Bon, G. (1896). The Crowd. A study of the popular mind. 2001. Kitchener: Batoche Books.

Mehta, V., \& Bosson, J. K. (2018). Revisiting Lively Streets: Social Interactions in Public Space. Journal of Planning Education and Research.

Nasution, A. D., \& Zahrah, W. (2018). Quality of Life : Public open space effects. Asian Journal of Environment-Behaviour Studies, 3(10), 124.

Polansky, N., Lippitt, R., \& Redl, F. (1950). An investigation of behavioral contagion in groups. Human Relations.

Redl, F. (1949). The phenomenon of contagion and "shock effect" in group therapy. In Searchlights on delinquency; new psychoanalytic studies. (pp. 315-328). Oxford, England: International Universities Press.

Rubin, G. J., Amlôt, R., Page, L., \& Wessely, S. (2009). Public perceptions, anxiety, and behaviour change in relation to the swine flu outbreak: Cross sectional telephone survey. BMJ (Online), 339(7713), 156.

Saunders, M., Lewis, P., \& Thornhill, A. (2009). Research Methods for business students (5th ed.). Pearson Education Limited.

Shirado, H., Crawford, F. W., \& Christakis, N. A. (2020). Collective communication and behaviour in response to uncertain 'Danger' in network experiments. Proceedings of the Royal Society A: Mathematical, Physical and Engineering Sciences, 476(2237).

Suzuki, S., Jensen, E. L. S., Bossaerts, P., \& O'Doherty, J. P. (2016). Behavioral contagion during learning about another agent's risk-preferences acts on the neural representation of decision-risk. Proceedings of the National Academy of Sciences of the United States of America, 113(14), 3755-3760.

UN-Habitat. (2013). Streets as Public Spaces and Drivers of Urban Prosperity. Nairobi.

van Baaren, R. (2007). Encyclopedia of Social Psychology. In Encyclopedia of Social Psychology. SAGE Publications.

Villanueva, K., Badland, H., Hooper, P., Koohsari, M. J., Mavoa, S., Davern, M., et al. (2015). Developing indicators of public open space to promote health and wellbeing in communities. Applied Geography, 57, 112-119.

Wheeler, L. (1966). Toward a theory of behavioral contagion. Psychological Review, 73(2), 179-192.

White, W. H. (1980). The Social Life of Small Urban Spaces. (P. for P. S. Inc, Ed.). New York: Project for Public Spaces Inc.

Zordan, M. (2018). Ground China. Starting from Villages. In Walkable Cities in High-Density China. Livable, Healthy and Sustainable (pp. 41-81). Shanghai: Tongji University Press. 